\title{
Prevalence of Major Fetal Defects in Fallujah, Iraq
}

\author{
Muntaha Al-Alwani ${ }^{*}$, Ahmed Sameer Alnuaimi2 \\ ${ }^{1}$ Mosul College of Medicine, University of Mosul, King's College Hospital, Mosul, Iraq \\ ${ }^{2}$ Department of Community Medicine, Baghdad College of Medicine, University of Baghdad, Baghdad, Iraq \\ Email: " muntaha gyn@yahoo.com
}

Received 10 April 2014; revised 8 May 2014; accepted 3 June 2014

Copyright (C) 2014 by authors and Scientific Research Publishing Inc.

This work is licensed under the Creative Commons Attribution International License (CC BY).

http://creativecommons.org/licenses/by/4.0/

(c) (i) Open Access

\begin{abstract}
Background: The prenatal prevalence of congenital anomalies in Iraq is still under debate because of deficiencies in diagnostic capabilities and low reliability of medical registration. Early antenatal diagnosis of fetal defects is important for early counseling, intervention and possible fetal therapy. Objectives: The aim of this study was to estimate prenatal frequency of major congenital anomalies and malformation patterns diagnosed by ultrasound in Fallujah city. Patients and Methods: A cross-sectional study using the recorded data of antenatal diagnosis of major fetal congenital anomalies conducted in Fallujah Hospital-Fetal Medicine Clinic for a period of 20 months (January 2012 to August 2013). During this period one or more obstetrical ultrasound examinations were performed for 2120 pregnant ladies. Results: A total of 178 cases with obvious fetal anomalies were diagnosed. The prenatal prevalence of congenital anomalies was 84 per 1000 . The median maternal age at diagnosis was $29 \pm 6.3$ years. The mean gestational age at diagnosis was 27 weeks \pm 5 days. Extremities and urinary system anomalies were the most frequently detected anomalies. Conclusion: The prevalence of structural fetal malformation diagnosed by ultrasound in Fallujah city is obviously higher than internationally reported figures.
\end{abstract}

\section{Keywords}

Antenatal Diagnosis, Fetal Anomalies, Fallujah, Obstetrical Ultrasound

\section{Introduction}

A congenital anomaly is an abnormality of structure or function of body that is present at birth, which could cause physical or mental disability, or sometimes result in fetal death. Major congenital malformations are re-

"Corresponding author. 
ported in at least $2 \%$ of all fetuses and infants and have a major impact on perinatal and infant morbidity in infancy and childhood. During the last decades an increasing number of congenital malformations have been diagnosed prenatally by ultrasound investigations [1].

Every year, eight million babies are born over the world with birth defects; 3.3 million of them die before 5 years old; 3.2 million of survivors may be either mentally or physically disabled [2].

The role of environmental pollutants, drugs and infectious agents in causing congenital anomalies is a major global concern. However, the underlying causes for the most congenital malformations remain obscure and multifactorial inheritance is believed to be the underlying etiology of most common abnormalities. $15 \%$ to $25 \%$ of congenital anomalies have been estimated due to recognized genetic conditions, $8 \%$ to $12 \%$ to environmental factors, and $20 \%$ to $25 \%$ to multifactorial. The majority of birth defects, $40 \%$ to $60 \%$, are unexplained. The registration and monitoring of the type and a number of anomalies are important to identify possible causes.

One of the purposes of prenatal diagnosis is to increase the possibility of optimal management of the pregnancy in terms of antenatal care, referral for birth to the required specialist level and planning of postnatal treatment of the baby. In the UK, the prevalence of birth defect is $2 \%$ to $3 \%$, while, about $3 \%$ in the USA [3]. In the UK, congenital anomalies account for $21 \%$ of perinatal and infant death [4]. In Saudi Arabia, a recent study estimated that the incidence of major and minor defects among live born infants is 27.1/1000 live births [5].

\section{Patients and Methods}

A cross-sectional study conducted at fetal medicine clinic in Fallujah General Hospital. The study was over 20-month period, from 1st of January 2012 to 15th of August 2013.

Fallujah is a small city located $60 \mathrm{~km}$ to the west of Baghdad, the population of the city and rural areas around it is 526,499 according to CSO (central statistics office) estimates. Number of deliveries in Fallujah city was 17,277 deliveries (in all pregnant women attended the fetal medicine clinic had an ultrasound examination either in first trimester, second trimester or third trimester).

All women with abnormal fetuses having either an antenatal diagnosis at or referred to the clinic with congenital anomalies were included in this study. About two fifths of study sample had 2 or more ultrasound examination. All ultrasound scans were performed using Voluson E6, BT10 (GE, Austria). All data sheet created for her at the time of diagnosis was used to record all general maternal information, fetal congenital anomalies and recommendations, using Astraia software for women's health.

Major congenital anomalies were divided according to the system involved (head, brain, neck, face, spine, thoracic, cardiac, abdominal wall, GIT, genitourinary system and skeletal). The fetuses were diagnosed as having either isolated anomalies or complex anomalies. Minor anomalies or soft markers were excluded from the study.

During the 20 month period study, 3531 ultrasound examinations were performed for 2120 pregnant ladies and prevalence of antenatal fetal anomalies was calculated from the total number of examined patients.

\section{Statistical Analysis}

Data were extracted from the Astraia software (used for antenatal registration of US examination findings) using custom SQL queries. Data was analyzed using IBM SPSS version 21. Frequency distribution for selected variables was done first. Cross-tabulations were tested for statistical significance using Chi-square test of independence. The difference in mean between 2 groups was tested by independent samples t-test.

\section{Results}

The results presented in this study were based on the analysis of 2120 pregnant females residing in Fallujah city with fetal US examinations. The age of study participants ranged between 14 to 50 years old with a mean \pm SD (29.1 \pm 6.3). Those less than 20 years constituted $5.8 \%$, while those older than 40 years constituted $5.6 \%$. A single US examination was performed for $59.6 \%$ of study sample. The remaining $40.4 \%$ of examined females had between 2 and up to 7 serial US examinations. For those with repeated US examinations the gestational age of the earliest exam was considered (since the highest probability of detecting fetal anomalies is in the first trimester), while for those with positive fetal anomalies detected the gestational age associated with the detection was considered. The gestational age for examined sample ranged between 6.4 and 43 weeks of gestation, with a 
mean \pm SD $(21.7 \pm 8.2$ weeks). Only 5 cases $(0.2 \%)$ had their US examination early in pregnancy $(<8$ weeks of gestation), 23.2\% had their examination the first trimester (8 - 14 weeks), about a half (52.1\%) had their examination on the second trimester, while only a quarter (24.5\%) had a late US exam (third trimester), Table 1.

The prevalence of a single fetal abnormality among examined pregnant females was 33.5 per 1000 pregnancies. A combination of 2 fetal anomalies was detected in 23.1 per 1000 examined pregnancies. A combination of at least 3 fetal anomalies (up to 7) was observed in 43.4 per 1000 pregnancies, Table 2.

As shown in Table 3, the most frequently found fetal abnormality was that of extremities, urinary tract, thoracic, brain, and the GIT with a prevalence rate of 28.8, 26.4, 25.5, 25 and 21.5 per 1000 examined pregnancies respectively. The least frequently reported fetal anomalies (found in less than 10 per 1000 pregnancies) were abnormal face, abnormal abdominal wall and abnormal genitalia. The prevalence rate of any positive visible fetal abnormality detected by US in the total sample of pregnant females in Fallujah city was 84 per 1000 pregnancies (expected range in the reference population was 72.2 to 95.8 per 1000 pregnancies with $95 \%$ confidence level).

Table 1. Frequency distribution of the study sample by selected variables.

\begin{tabular}{|c|c|}
\hline & $\mathrm{N}(\%)$ \\
\hline \multicolumn{2}{|l|}{ 1) Age group (years) } \\
\hline$<20$ & $123(5.8)$ \\
\hline $20-29$ & $1098(51.8)$ \\
\hline $30-39$ & $782(36.9)$ \\
\hline $40+$ & $117(5.5)$ \\
\hline Total & $2120(100)$ \\
\hline Range (14 to 50$)$ & \\
\hline Mean \pm SD $(29.1 \pm 6.3)$ & \\
\hline \multicolumn{2}{|l|}{ 2) Count of US exams for each study subject } \\
\hline 1 & $1253(59.6)$ \\
\hline 2 & $503(23.9)$ \\
\hline 3 & $203(9.7)$ \\
\hline 4 & $83(3.9)$ \\
\hline 5 & $37(1.8)$ \\
\hline 6 & $15(0.7)$ \\
\hline 7 & $8(0.4)$ \\
\hline Total & $2102(100)$ \\
\hline \multicolumn{2}{|c|}{ 3) Gestational age (the earliest in case of repeated US exams) } \\
\hline Early pregnancy ( $<8$ weeks) & $5(0.2)$ \\
\hline First trimester (8 - 14 weeks) & $487(23.2)$ \\
\hline Second trimester & $1096(52.1)$ \\
\hline Third trimester & $514(24.5)$ \\
\hline Total & $2102(100)$ \\
\hline \multicolumn{2}{|l|}{ Range (6.4 - 43) } \\
\hline Mean \pm SD $(21.7 \pm 8.2)$ & \\
\hline
\end{tabular}

Note: 18 cases had no gestational age saved in the database. 
Table 2. Frequency distribution of the study sample by selected variables.

\begin{tabular}{ccc}
\hline Count of visible fetal abnormalities detected by US & N (/1000) \\
\hline 7 & $1(0.5)$ \\
6 & $2(0.9)$ \\
5 & $2(0.9)$ \\
4 & $22(10.4)$ \\
2 & $31(14.6)$ \\
1 & $49(23.1)$ \\
None detected & $71(33.5)$ \\
Total & $1942(916)$ \\
\end{tabular}

Table 3. Frequency distribution of the study sample by selected variables.

\begin{tabular}{cc}
\hline Congenital anomalies (total examined = 2120) & N (/1000) - [95\% confidence interval] \\
\hline Extremities abnormalities & $61(28.8)-[(21.7-35.9)]$ \\
Urinary tract abnormalities & $56(26.4)-[(19.6-33.2)]$ \\
Thorax anomalies & $54(25.5)-[(18.8-32.2)]$ \\
Abnormalities of brain & $53(25)-[(18.4-31.6)]$ \\
GIT anomalies & $45(21.2)-[(15.1-27.4)]$ \\
Heart anomalies & $33(15.6)-[(10.3-20.8)]$ \\
Head anomalies & $22(10.4)-[(6.1-14.7)]$ \\
Spine anomalies & $19(9)-[(5-13)]$ \\
Abnormalities of neck and skin & $17(8)-[(4.2-11.8)]$ \\
Abdominal wall anomalies & $8(3.8)-[(1.2-6.4)]$ \\
Face anomalies & $8(3.8)-[(1.2-6.4)]$ \\
Abnormal genitalia & $3(1.4)-[(0.2-3)]$
\end{tabular}

As shown in Table 4, the highest detection rate for fetal anomalies (11.7\%) was in the third trimester, followed by a detection rate of $9.5 \%$ in the second trimester. The lowest detection rate was observed in the first trimester $(2.9 \%)$. The difference in detection rate between the 3 trimesters of pregnancies was statistically significant.

The detection rate (prevalence) of brain, face, GIT, urinary tract and extremities abnormalities was significantly higher in the 3rd and 2nd trimester of pregnancy compared to 1st trimester. A similar trend was observed for the remaining fetal anomalies, but the differences observed in detection rate between the 3 trimesters of pregnancy was not significant statistically, Table 5.

Fetal abnormalities were multiple (combination of 2 or more) in $66.5 \%$ of examined pregnancies with positive visible fetal abnormalities. All skeletal abnormalities detected (100\%) presented in combined form with other fetal anomalies. Abnormalities of extremities, neck/skin, heart, abdominal wall and GIT were more likely to be present in combinations of 2 or more (multiple). More than $90 \%$ of these types of fetal abnormalities presented in combinations. On the other hand abnormal urinary tract, brain and genitalia, were the least likely to present in 
Table 4. The rate of detection by gestational age categories.

\begin{tabular}{|c|c|c|c|c|}
\hline & \multicolumn{3}{|c|}{$\begin{array}{l}\text { Gestational age (the earliest in case of } \\
\text { repeated US exams) - categories }\end{array}$} & \multirow{3}{*}{$\mathrm{P}$} \\
\hline & $\begin{array}{l}\text { First trimester } \\
\text { (8-14 weeks) }\end{array}$ & Second trimester & Third trimester & \\
\hline & $\mathrm{N}(\%)$ & $\mathrm{N}(\%)$ & $\mathrm{N}(\%)$ & \\
\hline Any positive visible fetal abnormality detected by US & & & & $<0.001$ \\
\hline Negative (no abnormality noticed) & $473(97.1)$ & $992(90.5)$ & $454(88.3)$ & \\
\hline Positive (abnormal) & $14(2.9)$ & $104(9.5)$ & $60(11.7)$ & \\
\hline Total & $487(100)$ & $1096(100)$ & $514(100)$ & \\
\hline
\end{tabular}

Table 5. The positivity rate of selected fetal abnormalities by gestational age.

\begin{tabular}{|c|c|c|c|c|}
\hline \multirow{4}{*}{ Positive structural fetal anomalies } & \multicolumn{3}{|c|}{$\begin{array}{l}\text { Gestational age (the earliest in case of } \\
\text { repeated US exams) — categories }\end{array}$} & \multirow{4}{*}{$\mathrm{P}$} \\
\hline & $\begin{array}{l}\text { First trimester } \\
\text { (8 - } 14 \text { weeks) }\end{array}$ & Second trimester & Third trimester & \\
\hline & $\mathrm{N}(\%)$ & $\mathrm{N}(\%)$ & $\mathrm{N}(\%)$ & \\
\hline & $($ Total $n=487)$ & $($ Total $n=1096)$ & $($ Total $n=514)$ & \\
\hline Abdominal wall anomalies & $1(0.2)$ & $6(0.5)$ & $1(0.2)$ & $0.44[\mathrm{NS}]$ \\
\hline Abnormalities of brain & $4(0.8)$ & $31(2.8)$ & $18(3.5)$ & 0.017 \\
\hline Extremities abnormalities & $3(0.6)$ & $41(3.7)$ & $17(3.3)$ & 0.002 \\
\hline Face anomalies & $0(0)$ & $4(0.4)$ & $4(0.8)$ & $0.14[\mathrm{NS}]$ \\
\hline GIT anomalies & $4(0.8)$ & $19(1.7)$ & $22(4.3)$ & $<0.001$ \\
\hline Head anomalies & $3(0.6)$ & $14(1.3)$ & $5(1)$ & $0.48[\mathrm{NS}]$ \\
\hline Heart anomalies & $3(0.6)$ & $18(1.6)$ & $12(2.3)$ & $0.09[\mathrm{NS}]$ \\
\hline Abnormalities of neck and skin & $4(0.8)$ & $10(0.9)$ & $3(0.6)$ & $0.79[\mathrm{NS}]$ \\
\hline Spine anomalies & $3(0.6)$ & $10(0.9)$ & $6(1.2)$ & 0.65 [NS] \\
\hline Thorax anomalies & $6(1.2)$ & $33(3)$ & $15(2.9)$ & $0.1[\mathrm{NS}]$ \\
\hline Urinary tract abnormalities & $2(0.4)$ & $35(3.2)$ & $19(3.7)$ & 0.002 \\
\hline Abnormal genitalia & $1(0.2)$ & $0(0)$ & $2(0.4)$ & 0.14 [NS] \\
\hline Any positive visible fetal abnormality detected by US & $14(2.9)$ & $104(9.5)$ & $60(11.7)$ & $<0.001$ \\
\hline
\end{tabular}

combinations. Less than $70 \%$ of these types of fetal anomalies presented in combinations of 2 or more anomalies, Table 6.

As shown in Table 7, the rate of detected fetal anomalies was obviously lower (8\%) among older pregnant females (40+ years) compared to around $10 \%$ in the younger age group. The association between age and probability of having fetal anomaly was however, not significant statistically.

\section{Discussion}

A systematic search for online published articles about prenatal diagnosis of congenital anomalies in Iraq and Fallujah in particular failed to yield any. The present article is a humble contribution to address the antenatal detection rate of major congenital malformations diagnosed by ultrasound in Iraq. In addition it may contribute 
Table 6. The relative frequency of multiple abnormalities for different types of US detected abnormalities.

\begin{tabular}{|c|c|c|c|}
\hline \multirow{3}{*}{ Positive structural fetal anomalies } & \multicolumn{2}{|c|}{ Visible fetal abnormalities detected by US } & \multirow{2}{*}{ Total } \\
\hline & Single abnormality & Multiple abnormalities & \\
\hline & $\mathrm{N}(\%)$ & $\mathrm{N}(\%)$ & $\mathrm{N}(\%)$ \\
\hline Abdominal wall anomalies & $2(25)$ & $6(75)$ & $8(100)$ \\
\hline Abnormalities of brain & $16(30.2)$ & 37 (69.8) & $53(100)$ \\
\hline Extremities abnormalities & 7 (11.5) & $54(88.5)$ & $61(100)$ \\
\hline Face anomalies & $0(0)$ & $8(100)$ & $8(100)$ \\
\hline GIT anomalies & $9(20)$ & $36(80)$ & $45(100)$ \\
\hline Head anomalies & $5(22.7)$ & $17(77.3)$ & $22(100)$ \\
\hline Heart anomalies & $3(9.1)$ & $30(90.9)$ & $33(100)$ \\
\hline Abnormalities of neck and skin & $3(17.6)$ & $14(82.4)$ & $17(100)$ \\
\hline Spine anomalies & $1(5.3)$ & $18(94.7)$ & $19(100)$ \\
\hline Thorax anomalies & $2(3.7)$ & $52(96.3)$ & $54(100)$ \\
\hline Urinary tract abnormalities & $22(39.3)$ & $34(60.7)$ & $56(100)$ \\
\hline Abnormal genitalia & 1 (33.3) & $2(66.7)$ & $3(100)$ \\
\hline Any positive visible fetal abnormality detected by US & $71(39.9)$ & $107(60.1)$ & $178(100)$ \\
\hline Total & $71(39.9)$ & $107(60.1)$ & $178(100)$ \\
\hline
\end{tabular}

Table 7. The rate of having any positive visible fetal abnormality detected by US by age GROUP.

\begin{tabular}{|c|c|c|c|}
\hline & \multicolumn{2}{|c|}{ Any positive visible fetal abnormality detected by US } & \multirow{2}{*}{ Total } \\
\hline & Negative (no abnormality noticed) & Positive (abnormal) & \\
\hline & $\mathrm{N}(\%)$ & $\mathrm{N}(\%)$ & $\mathrm{N}(\%)$ \\
\hline \multicolumn{4}{|c|}{ Age group (years) } \\
\hline$<20$ & $113(91.9)$ & $10(8.1)$ & $123(100)$ \\
\hline $20-29$ & 1008 (91.8) & $90(8.2)$ & $1098(100)$ \\
\hline $30-39$ & $711(90.9)$ & $71(9.1)$ & $782(100)$ \\
\hline $40+$ & $110(94)$ & $7(6)$ & $117(100)$ \\
\hline
\end{tabular}

$\mathrm{P}($ Chi-square $)=0.67$ [NS].

to some extent in resolving the continuous debate about congenital anomalies in Fallujah. All the patients included in this study were from Fallujah city and rural areas around it (patients visiting the clinic from other cities were excluded).

The detection rate of structural abnormalities in Fallujah was 8.4\%, which is much higher than international figures. Although the prevalence of abnormalities depends upon the population being scanned, it does not show wide international variations, being in the range of $2 \%-3 \%$. The rate is about 3\% in the United States [6], 2.5\% in India [7], and $2 \%$ to $3 \%$ in the United Kingdom [8]. In Pakistan, the antenatal prevalence of congenital anomalies was $2.97 \%$. The high detection rate in Fallujah may be attributed in part to suspicious cases referred by obstetricians, which will definitely increase the detection rate, when they mix with surveyed cases as part of their antenatal care. The current study was hospital-based and does not represent the actual prevalence in Fallujah. This data should stimulate future research and collaboration for more accurate and complete reporting of major congenital anomalies. Such a high detection rate should raise the need for establishing a national registry 
of birth defects to monitor the epidemiology (occurrence, etiology, morbidity, mortality) of birth defects is an urgent need in Iraq.

The second argument that can be raised is that the reported figures are for prenatal diagnosis and not for actually seen birth defects in the new-born after labor. This should not undermine the benefit of the figures reported since; there is a significant relationship between prenatal detection and actual presence of malformations. For individual malformations, the prenatal detection rate was highest for anencephalus and lowest congenital heart disease [9].

The most prevalent conditions in the current study was skeletal system (extremities), followed by urinary system, thoracic abnormalities, brain abnormalities, GIT abnormalities, heart abnormalities, head abnormalities and spine abnormalities. In comparison to other studies, the most prevalent conditions include congenital heart defects [10], orofacial clefts, Down syndrome [11], and neural tube defects [12]. There are a number of laboratory and imaging studies available for detection of these anomalies. Out of these ultrasound is the one which gives a great amount of information about the structure and to some extent physiological aspects of the state of fetus. Some anomalies like anencephaly can be picked as early as 12 weeks when skull ossification is complete [13]. In Pakistan, central nervous system and musculo-skeloton were commonly diagnosed, fallowed genitourinary, renal and miscellaneous (hydropsfetalis, pleural effusion, etc.). However, facial and heart defects rarely found or more commonly missed [14]. In UAE, the major malformations at birth were classified as multiple or isolated single system abnormalities as well as genetic and non-genetic disorders. The most common systems involved in infants with isolated single system malformations include gastrointestinal, central nervous system, and cardiovascular respectably [15]. In Egypt, the postnatal major abnormalities were skeletal system anomalies, then chromosomal abnormalities, circulatory system anomalies, central nervous system (CNS) anomalies, genital organs anomalies, gastrointestinal tract (GIT) anomalies, eye and ear anomalies, and lastly urinary system [16].

Cardiac anomalies are one of the most common anomalies worldwide and at the same time the most commonly missed anomalies in antenatal ultrasound examination. This was the case in the current study. Many cardiac cases were most probably missed because of the unavailability of a pediatric cardiac surgeon at the hospital during the study period.

The perinatal mortality rate is expected to be higher with major congenital anomalies. It is strongly related to gestational age at delivery and the complexity of the anomalies. The association of genitourinary system anomalies and anhydramnios carries a very poor prognosis [17] [18].

Certain abnormalities are more easily detectable at $11-14$ weeks than others. First trimester sonography is particularly good for diagnosing central nervous system defects, neck anomalies, gastrointestinal and renal defects. However, spina-bifida, heart anomalies and limb defects are more difficult to detect. Recently, the presence of cranial signs in the first trimester (banana-shaped cerebellum and lemon shaped cranium) has a vital role in diagnosis of spinabifida [19].

The overall detection time varied from early to late pregnancy depending upon when the patient reports to hospital for antenatal checkup. Second trimester ultrasound scan has become an essential part of antenatal care. In cases where a major structural defect is identified, termination of pregnancy is offered [20]. The morbidity and mortality of this procedure increases with advancing gestation. Therefore early detection of such abnormalities will result in the reduction of such complications. The diagnostic ability of ultrasound is well established by a number of studies [21] [22]. The late gestational age at diagnoses is a major factor affecting proper antenatal diagnosis and outcome.

The lack of facilities like laboratory investigation, invasive testing and genetic studies have a role in not reaching the final diagnosis for some of major fetal defects. Late antenatal diagnosis is either due to late booking or late referral. Fetal medicine as a discipline is new in Iraq and a lot of physicians have no idea about the availability of this type of medical service. In addition, termination of pregnancy is not legal (or ethical) in Iraq. Thus, most women carry their pregnancies to term, unless a diagnosis of lethal anomalies such as anencephaly or bilateral renal agenesis is attached to the pregnancy. This might explain the highest detection of abnormalities in $3^{\text {rd }}$ trimester in our study.

In Iraq there is a need for addressing strategies for the prevention of congenital anomalies in Iraq. 1) Primary prevention of non-hereditary congenital anomalies is through the removal of known risk factors. The majority of identified causes of congenital anomalies are non-hereditary and the main preventive measures recommended and being tried in developing countries are: a) expansion of rubella immunization, b) access to family planning programs that include the encouragement to complete reproduction before 35 years of age, c) periconceptional 
supplementation of folic acid, and d) access to adequate prenatal care, including nutrition, control of maternal infections and avoidance of teratogens.

2) Prevention of congenital anomalies based on reproductive options by implement mass prenatal screening followed by prenatal diagnosis and fetal ultrasound in all pregnancies in a multi-step strategy of diagnosis of fetal anomalies which includes genetic counseling and offer of invasive procedure (amniocentesis and CVS) and eventual voluntary termination of pregnancies with fetal anomalies [23].

\section{Conclusion}

In conclusion, the detection rate of major congenital anomalies diagnosed by ultrasound in Fallujah population is obviously higher than international data.

\section{References}

[1] EUROCAT Working Group (2002) Appendix 7\&8 in Report 8: Surveillance of Congenital Anomalies in Europe 1980-1999. University of Ulster, Ulster.

[2] March of Dimes Resource Center (1998) Birth Defects. www.modimes.org

[3] Canfield, M.A., Honein, M.A., Yuskiv, N., Xing, J., Mai, C.T., Collins, J.S., Devine, O., Petrini, J., Ramadhani, T.A., Hobbs, C.A. and Kirby, R.S. (2006) National Estimates and Race/Ethnic-Specific Variation of Selected Birth Defects in the United States, 1999-2001. Birth Defects Research Part A, Clinical and Molecular Teratology, 76, 747-756. http://dx.doi.org/10.1002/bdra.20294

[4] Boyd, P.A., Armstrong, B., Dolk, H., Botting, B., Pattenden, S., Abramsky, L., Rankin, J., Vrijheid, M. and Wellesley, D. (2005) Congenital Anomaly Surveillance. England-Ascertainment Deficiencies in the National System. BMJ, 330, 27-31. http://dx.doi.org/10.1136/bmj.38300.665301.3A

[5] Canfield, M.A., Honein, M.A., Yuskiv, N., Xing, J., Mai, C.T., Collins, J.S., Devine, O., Petrini, J., Ramadhani, T.A., Hobbs, C.A. and Kirby, R.S. (2006) National Estimates and Race/Ethnic-Specific Variation of Selected Birth Defects in the United States, 1999-2001. Birth Defects Research Part A, Clinical and Molecular Teratology, 76, 747-756. http://dx.doi.org/10.1002/bdra.20294

[6] Sallout, B.I., Al Hoshan, M.S., Attyyaa, R.A. and Al Suleimata, A.A. (2008) Antenatal Diagnosis, Prevalence and Outcome of Major Congenital Anomalies in Saudi Arabia: A Hospital-Based Study. Annals of Saudi Medicine, 28, 272-276. http://dx.doi.org/10.4103/0256-4947.51703

[7] Patel, Z.M. and Adhia, R.A. (2005) Birth Defects Surveillance Study, Year 2005. Indian Journal of Pediatrics, 72, 489-491. http://dx.doi.org/10.1007/BF02724426

[8] Boyd, P.A., Armstrong, B., Dolk, H., Botting, B., Pattenden, S., Abramsky, L., Rankin, J., Vrijheid, M. and Wellesley, D. (2005) Congenital Anomaly Surveillance in England Ascertainment Deficiencies in the National System. BMJ, 330, 27-31. http://dx.doi.org/10.1136/bmj.38300.665301.3A

[9] Garne, E., Loane, M., Dolk, H., De Vigan, C., Scarano, G., Tucker, D., Stoll, C., Gener, B., Pierini, A., Nelen, V., Rösch, C., Gillerot, Y., Feijoo, M., Tincheva, R., Queisser-Luft, A., Addor, M.C., Mosquera, C., Gatt, M. and Barisic, I. (2005) Prenatal Diagnosis of Severe Structural Congenital Malformations in Europe. Ultrasound in Obstetrics \& Gynecology, 25, 6-11. http://dx.doi.org/10.1002/uog.1784

[10] Lin, A.E., Herring, A.H., Amstutz, K.S., Westgate, M.N., Lacro, R.V., Al-Jufan, M., Ryan, L. and Holmes, L.B. (1999) Cardiovascular Malformations: Changes in Prevalence and Birth Status, 1972-1990. American Journal of Medical Genetics, 84, 102-110. http://dx.doi.org/10.1002/(SICI)1096-8628(19990521)84:2<102::AID-AJMG4>3.0.CO;2-G

[11] Centers for Disease Control and Prevention (CDC) (2006) Improved National Prevalence Estimates for 18 Selected Major Birth Defects-United States, 1999-2001. Morbidity and Mortality Weekly Report, 54, 1301-1305.

[12] Wen, S.W., Liu, S., Joseph, K.S., Rouleau, J. and Allen, A. (2000) Patterns of Infant Mortality Caused by Major Congenital Anomalies. Teratology, 6, 342-346. http://dx.doi.org/10.1002/(SICI)1096-9926(200005)61:5<342::AID-TERA5>3.0.CO;2-7

[13] Smith, N.C. and Smith, A.P.M. (2002) Detection of Congenital Fetal Anomalies. In: Obstetric Ultrasound Made Easy, Churchill Livingstone, London, 42-43.

[14] Nayab, A., Irshad, A., Amir, H. and Nazia, P. (2010) Congenital Anomalies: Prevalence of Congenital Abnormalities in 2nd Trimester of Pregnancy in Madina Teaching Hospital, Faisalabad on Gray Scale Unltrasound. JUMDC, 1, 2328.

[15] Al-Gazali, L.I., Dawodu, A.H., Sabarinathan, K. and Varghese, M. (1995) The Profile of Major Congenital Abnormalities in the United Arab Emirates (UAE) Population. Journal of Medical Genetics, 32, 7-13.

http://dx.doi.org/10.1136/jmg.32.1.7 
[16] Mohammed, Y.A., Shawky, R.M., Soliman, A.A. and Ahmed, M.M. (2011) Chromosomal Study in Newborn Infants with Con-Genital Anomalies in Assiut University Hospital: Cross-Sectional Study. The Egyptian Journal of Medical Human Genetics, 12, 79-90. http://dx.doi.org/10.1016/j.ejmhg.2011.02.003

[17] Alaani, S., Al-Fallouji, M.A., Busby, C. and Hamdan, M. (2012) Pilot Study of Congenital Anomaly Rates at Birth in Fallujah, Iraq. Journal of the Islamic Medical Association of North America, 44, 44-1-10463.

[18] Abdulghani, S.T., Hameed, A.A. and Alfayadh, Z.T. (2013) Causes and Differentials of Infant Mortality in the Pediatrics Wards in Fallujah General Hospital. British Journal of Medicine \& Medical Research, 3, 1178-1186. http://dx.doi.org/10.9734/BJMMR/2013/2333

[19] Sebire, N.J., Noble, P.L., Thorpe-Beeston, J.G., Snijders, R.J.M. and Nicolaides, K.H. (1997) Presence of the “Lemon” Sign at the 10 - 14 Week Scan. Ultrasound in Obstetrics Gynecology, 10, 403-405. http://dx.doi.org/10.1046/j.1469-0705.1997.10060403.x

[20] Royal College of Obstetricians and Gynecologists (1997) Report of the Working Party on Ultrasound Screening for Fetal Abnormalities. Royal College of Obstetricians and Gynecologists, London.

[21] Lee, K., Kim, S.Y., Choi, S.M., et al. (1998) Effectiveness of Prenatal Ultrasonography in Detecting Fetal Anomalies and Perinatal Outcome of Anomalous Fetuses. Yonsei Medical Journal, 39, 372-382.

[22] Dastigiri, S., Stone, D.H., Le-Ha, C. and Gilmour, W.H. (2002) Prevalence of Congenital Anomalies in Glasgow, UK. Archives of Disease of Childhood, 86, 257-263. http://dx.doi.org/10.1136/adc.86.4.257

[23] Penchaszadeh, V.B. (2002) Preventing Congenital Anomalies in Developing Countries. Community Genetics, 5, 61-69. http://dx.doi.org/10.1159/000064632 